Naturwissenschaften 75, $571-573(1988)$ @ Springer-Verlag 1988

\section{Catalytic Dissoluion of Iron(III)(hydr)oxides by Oxalic Acid in the Presence of Fe(II)}

\section{Suter, C. Siffert, B. Sulzberger, and W. Stumm}

Institute for Water Resources and Water Pollution Control, EAWAG, Swiss Federal Institute of Technology, $\mathrm{CH}-8600$ Duebendorf-Zurich

The dissolution of iron(III)(hydr)oxides is usually enhanced by $\mathrm{H}^{+}$ions, complex-forming substances (ligands) and by reductants. In natural systems, such as rocks, soils, and waters, biota can assist the dissolution by providing hydrogen ions (e.g., as a product of microbial respiration of organic matter), biogenic ligands such as oxalate, and other organic acids (exuded by plants and microorganisms) and reductants. The dissolution of ion(III)(hydr)oxides is also of practical importance in the iron cycle of biological systems, in corrosion (passive films), in the extraction of metals from ores, and in the removal of metal oxide deposits from metal surfaces.

Surface processes rather than transport processes are usually the rate-con- trolling steps in the dissolution of most slightly soluble oxides. We have illustrated $[1-3]$ that most of the dissolution reactions are critically dependent on the interaction of surface oxoand hydroxo-groups with $\mathrm{H}^{+}, \mathrm{OH}^{-}$, and suitable ligands (anions and weak acids). The mechanisms were described by the attachment of protons or ligands to the reaction sites prior to the detachment of the metal species.

In reductive dissolution of iron(III)(hydr)oxides, some of the iron(III) ions at the surface become reduced to iron(II). The latter are more easily released than iron(III) ions because the bonds between the reduced iron and its neighbor irons are weakened.

The various possible pathways for the dissolution of iron(III)(hydr)oxides are given schematically in Eqs. $(1-3)$ : 


$$
\begin{aligned}
& >\mathrm{Fe}^{\mathrm{III}}-\mathrm{OH}+\mathrm{H}^{+} \rightleftharpoons>\mathrm{Fe}^{\mathrm{III}}-\mathrm{OH}_{2}+\stackrel{\mathrm{H}_{2} \mathrm{O}}{\longrightarrow}>. .+\mathrm{Fe}^{\mathrm{III}}(\mathrm{aq}) \\
& >\mathrm{Fe}^{\mathrm{III}}-\mathrm{OH}+\mathrm{HL}^{-} \rightleftharpoons>\mathrm{Fe}^{\mathrm{III}}-\mathrm{L}^{-}+\mathrm{H}_{2} \mathrm{O} \stackrel{\mathrm{HL}}{\longrightarrow}>. .+\mathrm{Fe}^{\mathrm{III}} \mathrm{L}_{\mathrm{n}} \\
& >\mathrm{Fe}^{\mathrm{III}}-\mathrm{OH}+\mathrm{HR}^{-} \rightleftharpoons>\mathrm{Fe}^{\mathrm{III}}-\mathrm{R}^{-}+\mathrm{H}_{2} \mathrm{O} \stackrel{\mathrm{ET}}{\longrightarrow}>\mathrm{Fe}^{\mathrm{II}}-\mathrm{OH}_{2}+\mathrm{R}^{\cdot} \\
& \stackrel{\mathrm{H}_{2} \mathrm{O}}{\longrightarrow}>. .+\mathrm{Fe}^{\mathrm{II}}(\mathrm{aq})
\end{aligned}
$$

$>\mathrm{Fe}^{\mathrm{III}}-\mathrm{OH}$ stands for a peripheral iron(III) site and $>$.. symbolizes a surface site from which an $\mathrm{Fe}$ ion has been detached. HL is a ligand able to form a surface complex; HR is a reducing ligand that can form surface complexes; $\mathbf{R}^{\cdot}$ is its oxidation product; ET refers to electron transfer. The charges assigned in Eqs. $(1-3)$ are a conventional way of indicating correct relative values.

Equations (1) and (2) show the influence of protons and of surface complex-forming ligands, respectively. The fast binding of protons and/or ligands by the surface results in the weakening of the bonds in the immediate proximity of a surface iron(III) ion; this is followed by a slow detachment of the aquo iron(III) or iron(III) ligand complex species from the surface into the solution. Bidentate ligands like oxalate are especially efficient in enhancing the dissolution.

It is well known that a combination of a reductant and a complex former is very efficient in promoting fast dissolution of iron(III)(hydr)oxides [4]. Examples are the pairs dithionite/citrate and ascorbate/oxalate.

Here we report on the catalytic effect of $\mathrm{Fe}$ (II) on the dissolution of hematite and goethite by oxalate. Although oxalate alone dissolves iron(III)(hydr)oxides at a considerable rate, in the presence of small concentrations of iron(II) and the same concentrations of oxalate, the dissolution rate is increased remarkably [5]. The combination of ferrous iron and oxalate is a special case of a dissolution with a reductant and a complex former. [Ferrous iron oxalate complex is the reductant and oxalate is also acting as a ligand for surface iron(III)].

Our experiments were performed in the dark at $20^{\circ} \mathrm{C}$ with hematite that was prepared according to [8]. The surface area was determined as the adsorption capacity for fluoride at $\mathrm{pH}$ 3.5. The value for hematite was $1.5 \times 10^{-4} \mathrm{~mol}$ $\mathrm{g}^{-1}$, corresponding to about $10 \mathrm{~m}^{2} \mathrm{~g}^{-1}$. Dissolution measurements were made at $\mathrm{pH}$ values ranging from 2 to 4 . The dissolution was determined by analyzing $\mathrm{Fe}$ (III) and $\mathrm{Fe}$ (II) in the filtrate of the suspension. Fe(II) was measured spectrophotometrically as the phenan-

throline complex. For the determination of $\mathrm{Fe}$ (III), we measured the total concentration of iron by reducing the ferric iron with hydroxylammonium sulfate and subtracted the initial concentration of ferrous iron from the total iron.

Representative experimental results on the dissolution of hematite in the presence of oxalate and $\mathrm{Fe}(\mathrm{II})$ are given in Fig. 1. The dissolution rates [mol Fe(III) released per hour and per mol fluoride exchangeable surface- $\mathrm{OH}$ ] for different experimental conditions are given in Fig. 2a. Similar results were obtained using goethite instead of hematite.

It is interesting to note that the total amount of iron(III) dissolved during an experiment is much higher than the amount or iron(II) present, indicating that the iron(II) is acting as a catalyst. There is no net reduction although the

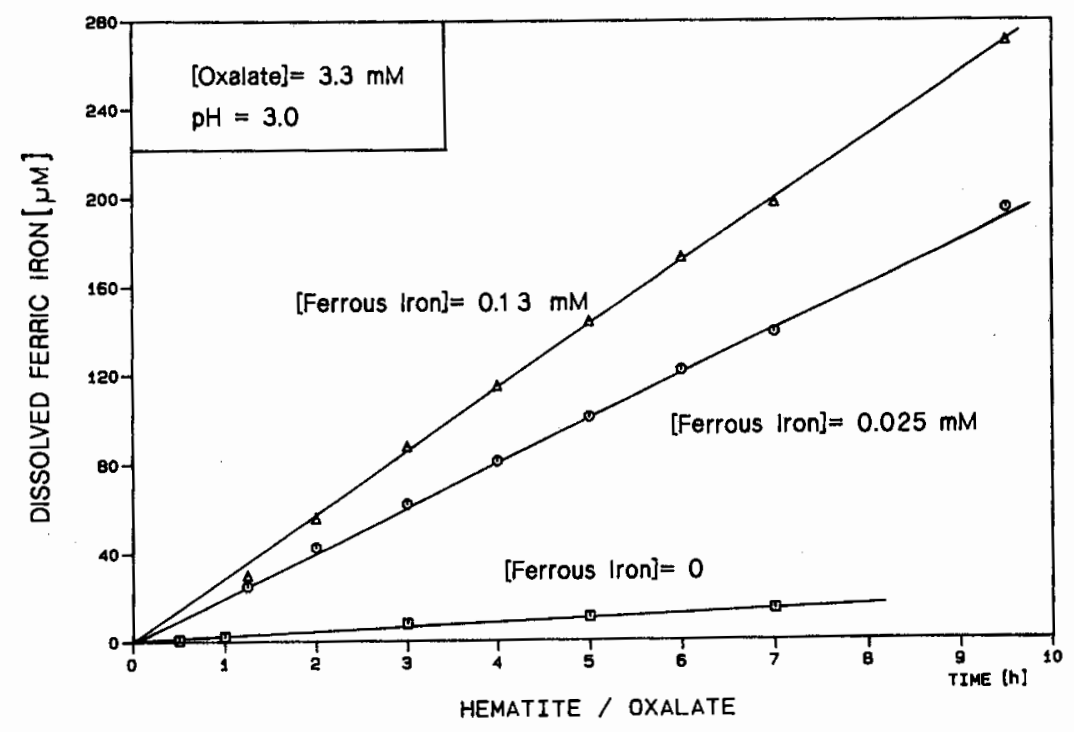

Fig. 1. Dissolved ferric iron as a function of time with different concentrations of ferrous iron
Naturwissenschaften 75 (1988) C Springer-Verlag 1988

Fig. 1. Dissolved ferric iron as a function of time with different concentrations of ferrous iron
Naturwissenschaften 75 (1988) C Springer-Verlag 1988

Fig. 1. Dissolved ferric iron as a function of time with different concentrations of ferrous iron
Naturwissenschaften 75 (1988) C Springer-Verlag 1988

reduction of the surface iron(III) has a strong effect on the kinetics of the reaction. At low pH, ferrous iron does not react with a solid iron(III)(hydr)oxide in the absence of a complex former. An added ligand like oxalate changes the situation in several ways:

Oxalate (i) complexes ferrous iron and the resulting complex is a stronger reductant than the aquo ion; (ii) is specifically bound to the surface iron(III), both as a bidentate and a monodentate complex [6]; (iii) forms ternary complexes with surface iron(III) and iron(II), thus binding ferrous iron to the surface; (iv) can act as an electron bridge for the transfer of an electron between iron(II) and the surface iron(III) [7]

The mechanism can be depicted as follows:

$$
\begin{aligned}
& >\mathrm{Fe}^{\mathrm{III}}-\mathrm{OH}+\mathrm{HC}_{2} \mathrm{O}_{4}^{-} \\
& \rightleftharpoons>\mathrm{Fe}^{\mathrm{III}}-\mathrm{C}_{2} \mathrm{O}_{4}^{-}+\mathrm{H}_{2} \mathrm{O} \\
& >\mathrm{Fe}^{\mathrm{III}}-\mathrm{C}_{2} \mathrm{O}_{4}^{-}+\mathrm{Fe}^{2+} \\
& \rightleftharpoons>\mathrm{Fe}^{\mathrm{III}}-\mathrm{C}_{2} \mathrm{O}_{4}-\mathrm{Fe}^{\mathrm{II}+} \\
& >\mathrm{Fe}^{\mathrm{III}}-\mathrm{C}_{2} \mathrm{O}_{4}-\mathrm{Fe}^{\mathrm{II}+}+\mathrm{HC}_{2} \mathrm{O}_{4}^{-} \\
& \rightleftharpoons>\mathrm{Fe}^{\mathrm{III}}-\mathrm{C}_{2} \mathrm{O}_{4}-\mathrm{Fe}^{\mathrm{II}}-\mathrm{C}_{2} \mathrm{O}_{4}^{-}+\mathrm{H}^{+} \\
& >\mathrm{Fe}^{\mathrm{III}}-\mathrm{C}_{2} \mathrm{O}_{4}-\mathrm{Fe}^{\mathrm{II}}-\mathrm{C}_{2} \mathrm{O}_{4}^{-} \\
& \stackrel{\mathrm{ET}}{\rightarrow} \mathrm{Fe}^{\mathrm{II}}-\mathrm{C}_{2} \mathrm{O}_{4}-\mathrm{Fe}^{\mathrm{III}}-\mathrm{C}_{2} \mathrm{O}_{4}^{-} \\
& >\mathrm{Fe}^{\mathrm{II}}-\mathrm{C}_{2} \mathrm{O}_{4}-\mathrm{Fe}^{\mathrm{III}}-\mathrm{C}_{2} \mathrm{O}_{4}^{-} \\
& \rightarrow>\mathrm{Fe}^{\mathrm{II}}+\mathrm{Fe}^{\mathrm{III}}\left(\mathrm{C}_{2} \mathrm{O}_{4}\right)_{2}^{-} \\
& >\mathrm{Fe}^{\mathrm{II}} \rightarrow>. .+\mathrm{Fe}^{\mathrm{II}}(\mathrm{aq})
\end{aligned}
$$



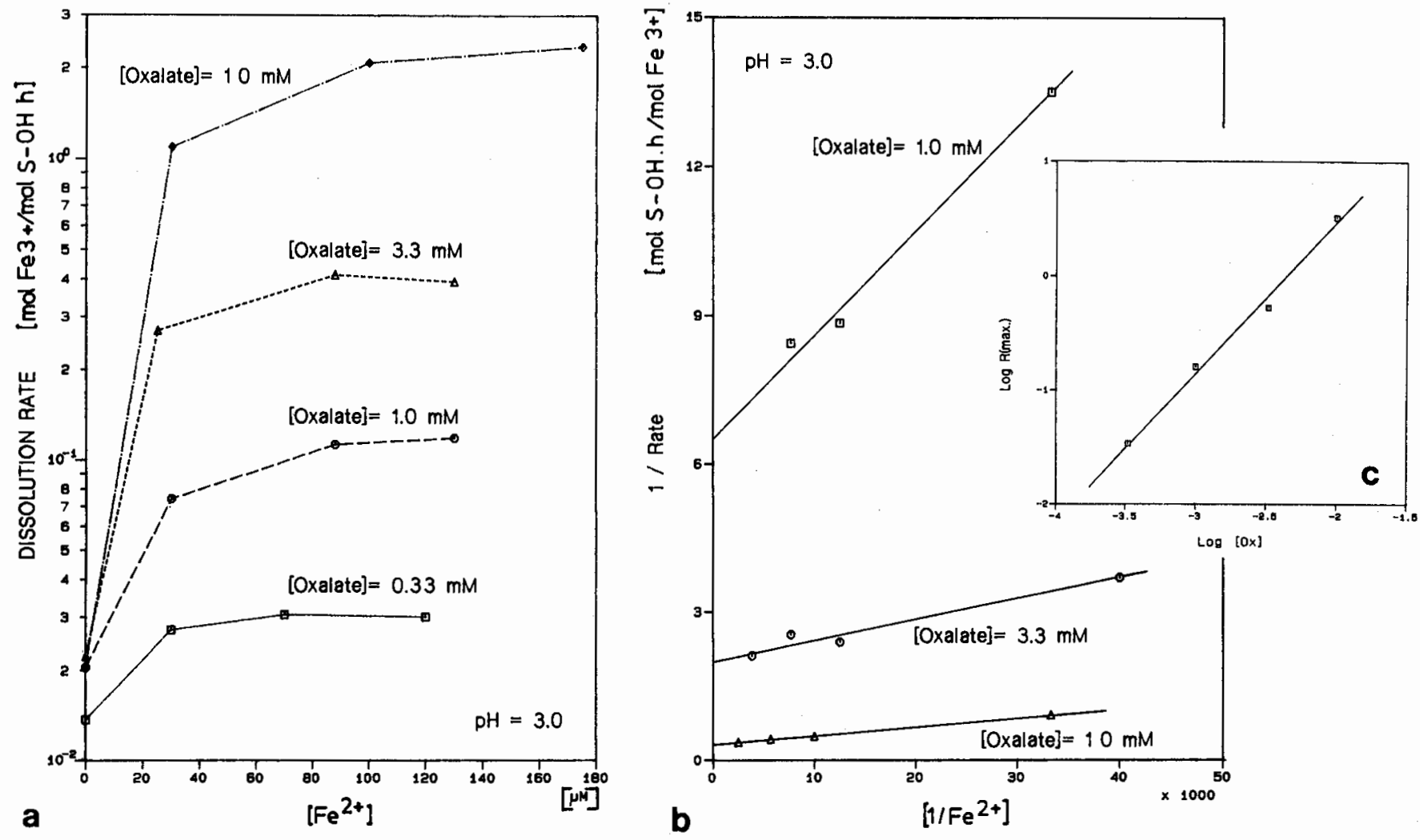

Fig. 2. a) Dissolution rates as a function of ferrous iron concentration. b) Plot of inverse dissolution rates as a function of inverse ferrous iron concentration. c) Maximum dissolution rates (derived from $b$ ) as a function of oxalate concentration

Figure 2a shows that the dissolution rate depends on the concentration of oxalate. Adsorption experiments showed that the adsorption on hematite and goethite is almost constant at all the oxalate concentrations we used, so the strong dependence on the oxalate concentration can only be explained by an increasing fraction of the adsorbed ferrous iron that is complexed with oxalate and only this surface complex can reduce the ferric iron of the lattice. The graphs in Fig. 2a can be linearized by plotting the inverse dissolution rates versus the inverse ferrous iron concentrations as shown in Fig. 2b. The intercepts give us the maximum dissolution rate at a given oxalate concentration. These maximum rates are proportional to the oxalate concentration in solution which is consistent with our assumption about the role of oxalate (Fig. $2 \mathrm{c}$ ).

The interpretation given here is a variation of that given in [9] for the acceleration of the dissolution of magnetite by oxalate. These investigators show that the dissolution rate is proportional to $\left[\mathrm{Fe}^{\mathrm{Il}}\left(\mathrm{C}_{2} \mathrm{O}_{4}\right)^{2-}\right]$ in solution and imply that the oxalate complexes become adsorbed at the interface and induce dissolution subsequent to an outer-sphere electron transfer. The tendency to form ternary surface complexes is relatively similar to the tendency to form ferrous dioxalato complexes.
Received August 11, 1988

1. Furrer, G., Stumm, W.: Geochim. Cosmochim. Acta 50, 1847 (1986)

2. Zinder, B., Furrer, G., Stumm, W.: ibid. 50, 1861 (1986)

3. Wieland, E., Wehrli, B., Stumm, W.: ibid. (submitted)

4. Schwertmann, U.: Z. Pflanzenernaehr. Bodenk. 105, 194 (1964)

5. Fischer, W. R., in: Pseudogley and Gley (Schlichting, E., Schwertmann, U., eds.). Weinheim: Verlag Chemie 1972

6. Parfitt, R. L., Farmer, V. C., Russell, J. D.: J. Soil. Sci. 28, 29 (1978)

7. Taube, H.: J. Am. Chem. Soc. 77, 4481 (1955)

8. Matijevic, E., Schreiner, P.: J. Coll. Interf. Sci. 63, 509 (1978)

9. Blesa, M. A., et al.: Inorg. Chem. 26, 3713 (1987) 